\title{
\begin{tabular}{|c|}
\hline CP \\
\hline OBGYN \\
\hline
\end{tabular}
}

Clinical Perspectives in Obstetrics and Gynecology

Series Editor:

Herbert J. Buchsbaum, M.D. 
\begin{tabular}{|c|}
\hline CP \\
\hline OBGYN Clinical Perspectives in Obstetrics and Gynecology \\
\hline
\end{tabular}

perspective noun: . . . the capacity to view subjects in their true relations or relative importance.

Each volume in Clinical Perspectives in Obstetrics and Gynecology will cover in depth a major clinical area in the health care of women. The objective is to present to the reader the pathophysiologic and biochemical basis of the condition under discussion and to provide a scientific basis for clinical management. These volumes are not intended as "how to" books, but as a ready reference by authorities in the field.

Though the obstetrician and gynecologist may be the primary provider of health care for the female, this role is shared with family practitioners, pediatricians, medical and surgical specialists, and geriatricians. It is to all these physicians that the series is addressed.

Series Editor: Herbert J. Buchsbaum, M.D.

Published Volumes:

Buchsbaum (ed.): The Menopause

Aiman (ed.): Infertility

Futterweit: Polycystic Ovarian Disease

Lavery and Sanfilippo (eds.): Pediatric and Adolescent Obstetrics and Gynecology

Galask and Larsen (eds.): Infectious Diseases in the Female Patient

Buchsbaum and Walton (eds.): Strategies in Gynecologic Surgery

Szulman and Buchsbaum (eds.): Gestational Trophoblastic Disease

Forthcoming Volumes:

Cibils (ed.): Surgical Diseases in Pregnancy

Collins (ed.): Ovulation Induction

Redmond (ed.): Lipids and Women's Health 


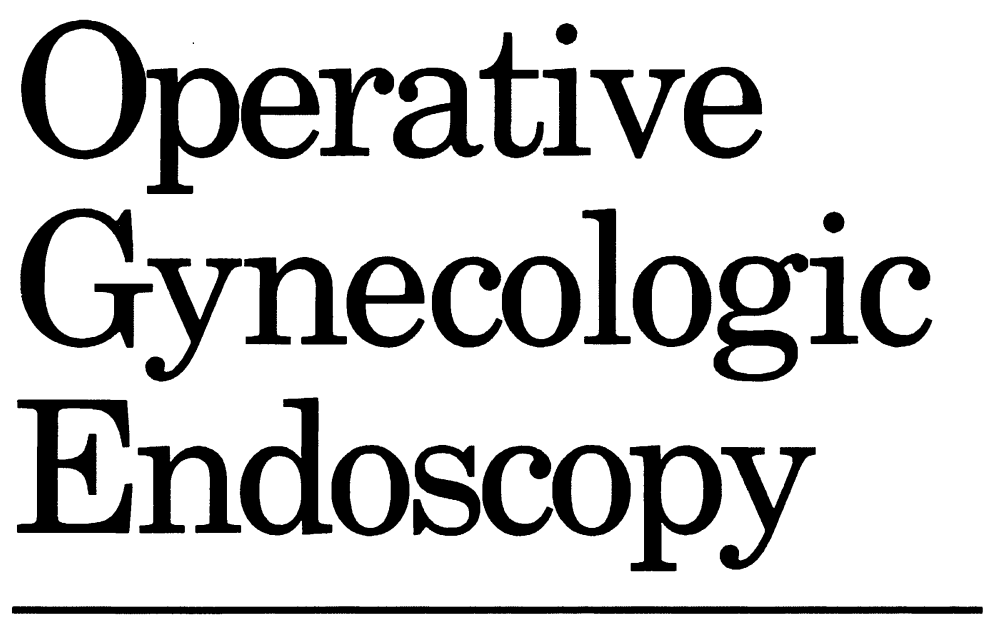

J.S. Sanfilippo · R.L. Levine Editors

With 156 Illustrations

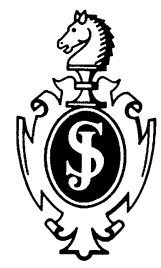

Springer Science+Business Media, LLC 


\title{
Editors:
}

Joseph S. Sanfilippo, M.D., Professor, Department of Obstetrics and Gynecology, University of Louisville School of Medicine, Louisville, Kentucky, USA

Ronald L. Levine, M.D., Clinical Professor, Department of Obstetrics and Gynecology, University of Louisville School of Medicine, Louisville, Kentucky, USA

\section{Series Editor:}

Herbert J. Buchsbaum, M.D., Professor and Chairman, Department of Obstetrics and Gynecology, Medical College of Wisconsin, Milwaukee, Wisconsin, USA

\author{
Library of Congress Cataloging-in-Publication Data \\ Operative gynecologic endoscopy/edited by Joseph S. Sanfilippo, \\ Ronald L. Levine. \\ p. cm.-(Clinical perspectives in obstetrics and \\ gynecology) \\ Includes index.
}

1. Generative organs, Female-Endoscopic surgery. 2. Generative organs, Female-Laser surgery. 3. Gynecology, Operative.

I. Sanfilippo, J. S. (Joseph S.) II. Levine, Ronald L.

\section{Series.}

[DNLM: 1. Endoscopy. 2. Genitalia, Female-surgery. 3. Laser

Surgery. WP 660 061]

RG104.064 1989

618.1'45-dc19

(C) 1989 by Springer Science+Business Media New York

Originally published by Springer-Verlag New York Inc in 1989.

Softcover reprint of the hardcover 1st edition 1989

\begin{abstract}
All rights reserved. This work may not be translated or copied in whole or in part without the written permission of the publisher

Springer Science+Business Media, LLC , except for brief excerpts in connec-

tion with reviews or scholarly analysis. Use in connection with any form of information storage and retrieval, electronic adaptation, computer software, or by similar or dissimilar methodology now known or hereafter developed is forbidden.

The use of general descriptive names, trade names, trademarks, etc. in this publication, even if the former are not especially identified, is not to be taken as a sign that such names, as understood by the Trade Marks and Merchandise Marks Act, may accordingly be used freely by anyone.

While the advice and information in this book are believed to be true and accurate at the date of going to press, neither the authors nor the editors nor the publisher can accept any legal responsibility for any errors or omissions that may be made. The publisher makes no warranty, express or implied, with respect to the material contained herein.
\end{abstract}

Media conversion by Bi-Comp, Inc., York, PA.

ISBN 978-1-4684-0332-9 ISBN 978-1-4684-0330-5 (eBook)

DOI $10.1007 / 978-1-4684-0330-5$

987654321 
To our families for their patience and to our patients whom we care for as family. 


\section{Preface}

It is becoming rapidly apparent that the discipline of gynecologic surgery is evolving into a specialty of increasing outpatient surgical expertise. Our mission in offering a comprehensive textbook on advanced endoscopic surgery and laser laparoscopy is to contribute to the education of interested clinicians and residents. We believe that an orderly sequencing of learning and application of knowledge is needed, and we think this text fits well into that sequence. This book allows the physician with skills in laparoscopy to gain the knowledge necessary to practice in the laboratory and ultimately to perform advanced endoscopic gynecologic surgery.

If indeed many current gynecologic procedures may be accomplished via endoscopic surgery, the clinician must have a reference to use when acquiring these skills. To quote Dr. Alan DeCherney (Fertil Steril 1985; 44:299): "The obituary of laparotomy for pelvic reconstructive surgery has been written; it is only its publication that remains."

The contributors to this text were chosen not only for their expertise but also for their clinical acumen in the field of endoscopic surgical application; both have been gained in a variety of American hospital settings, ranging from a small community hospital to a large urban university medical center. Because the number of contributors to this volume is large, some overlap of information is inevitable. We believe this approach enhances the usefulness of the textbook, as the reader may view each chapter as a self-contained work.

In April 1986 the first university course on operative laparoscopy in the United States was held in Louisville, Kentucky. Several members of that faculty have contributed to this text. It quickly became evident from the enthusiasm and interest among the faculty and participants at that meeting that a new era of operative gynecologic endoscopy was emerging. All of us were aware of the dearth of American input in this area of advanced gynecologic endoscopy. One of the goals of our book, therefore, has been to consider many of the unique aspects of practicing gynecologic endoscopy in America. 
The interest in "what can be accomplished through the laparoscope" has enjoyed an exponential growth, fueled by the use of laser technology and the increasing availability of proper instrumentation for what is also termed pelviscopic surgery. The reader may note that the terms pelviscopic surgery and operative laparoscopy are used synonymously in this text. For consistency, we have made an effort to use the term operative laparoscopy, as it is the preferred, more widely understood designation in the United States. We concede that at present there is no consensus within the medical community about terminology; several contributors to this text favor the term pelviscopic surgery as more descriptive. Just as the terms laparotomy and celiotomy or Stein-Leventhal syndrome and polycystic ovarian disease are recognized as interchangeable, so we consider operative laparoscopy and pelviscopic surgery to be equivalent.

We have long been convinced of the benefits of this new modality for our patients. We believe that the material contained in this text will help to improve the health care of gynecologic patients and will have a substantial beneficial economic impact on the practice of gynecology. Significant reduction in health care costs has been a direct result of the application of advanced gynecologic surgical procedures, as addressed in one of our previous publications ( $J$ Reprod Med $1985 ; 30: 655)$. That paper reported a $69 \%$ reduction in the number of postoperative hospital days required for operative laparoscopy compared to those needed for laparotomy and an overall $49 \%$ reduction in hospitalization costs for identical surgical procedures performed via pelviscopic surgery compared to the cost for laparotomy.

We hope that this text will contribute to the education of interested clinicians, residents, and students, and perhaps inspire them toward safer and more imaginative applications of endoscopic surgery.

Acknowledgments. We wish to acknowledge the many authors and consultants for their excellent contributions, assistance, and advice. In particular, we are indebted to Douglas $M$. Haynes, M.D., for his excellent translation of Professor Kurt Semm's chapter on the history of this procedure as well as for his scholarly guidance. We owe many thanks to Leon Goldman, M.D., for his constructive thoughts and consultation. We also wish to express our sincere appreciation for the assistance and patience of Leta N. Weedman, our editorial assistant. Our gratitude goes also to Mary Milliner and Betty Jones for manuscript preparation and word processing.

We must give special thanks to the University of Louisville School of Medicine in its sesquicentennial year for creating an environment conducive to meeting new challenges and to our 
colleagues in the Department of Obstetrics and Gynecology for their encouragement. The Department has always supported, both physically and ideologically, the acceptance of avant-garde ideas and techniques.

Last but not least, we must acknowledge the support and guidance of our wives, Patricia and Sonia, and our families. We thank them not only for their help and forbearance but most importantly for understanding the demands of our "mistress medicine."

Joseph S. Sanfilippo Ronald L. Levine 


\section{Contents}

Preface......................... vii

Contributors $\ldots \ldots \ldots \ldots \ldots \ldots \ldots \ldots \ldots \ldots \ldots \ldots \ldots \ldots \ldots \ldots$

I Operative Laparoscopy

1 History

Kurt Semm, translated by Douglas M. Haynes .... 1

2 Instrumentation

Ronald L. LeVInE. . . . . . . . . . . . . . . . . . 19

3 Techniques

John M. Leventhal . . . . . . . . . . . . . . 38

4 Open Laparoscopy

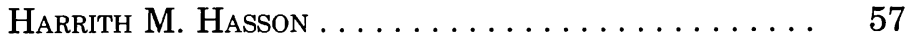

5 Ectopic Pregnancy

HARRY REICH. . . . . . . . . . . . . 68

6 Ovarian Surgery

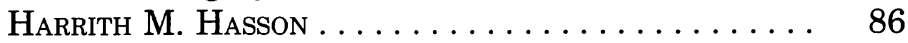

7 Pelvic Inflammatory Disease: Pathophysiology and Medical Management

David Charles and Bryan Larsen ........... 107

8 Endoscopic Management of Tuboovarian Abscess and Pelvic Inflammatory Disease

HARRY REICH. . . . . . . . . . . . . . . . 118

9 Myomectomy

Ronald L. Levine. . . . . . . . . . . . . . . . 133

10 Tubal Reconstructive Surgery

John M. Leventhal . . . . . . . . . . . . . . . . . . . . . 140

11 Visual Documentation

John M. Leventhal . . . . . . . . . . . . . . . . . . 148 
12 Anesthesia

Linda F. Lucas and Benjamin M. Rigor. . . . . . . . 162

13 Operating Room Personnel

Carolyn J. Mackety . . . . . . . . . . . . . . . 179

II Laser Laparoscopy

14 Laser Biophysics and Principles of Control

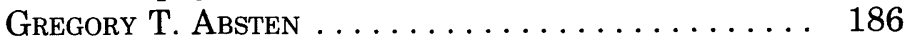

15 Laser Equipment

JoHn L. MARLOW. . . . . . . . . . . . . . . . . . . . 201

16 Laser Laparoscopy for Infertility Surgery

Dan C. Martin, Michael P. Diamond, and Marvin

A. Yussman $\ldots \ldots \ldots \ldots \ldots \ldots \ldots \ldots \ldots \ldots \ldots \ldots$

17 Endometriosis

Joseph S. SANFILIPPo $\ldots \ldots \ldots \ldots \ldots \ldots \ldots \ldots \ldots$

III Hysteroscopic and Laser Surgery

18 Diagnostic and Operative Hysteroscopy

JAMIL A. FAYEZ . . . . . . . . . . . . . . . . . . . 251

19 Hysteroscopic Laser Surgery

James F. Daniell . . . . . . . . . . . . . . . . 263

20 Urethrocystoscopy

Alfrep E. Bent and Donald R. Ostergard . . . . . . . 272

IV General Considerations of Endoscopy

21 Legal Issues Relating to Gynecologic Endoscopy

Steven R. Sмith. . . . . . . . . . . . . . . 281

22 Economic Impact of Gynecologic Endoscopy

Michael W. Method and Louis G. Keith. . . . . . . . 299

23 Clinical Perspectives and Credentialing

Carl J. Levinson . . . . . . . . . . . . . . . . . . . 308

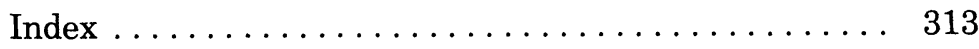




\section{Contributors}

Gregory T. Absten, M.A.

President, Advanced Laser Services Corporation, Grove City, Ohio, USA; Consultant, Ohio State University Hospitals, Columbus, Ohio, USA

Alfred E. Bent, M.D.

Assistant Professor of Obstetrics and Gynecology, University of California at Irvine, Irvine, California, USA; Assistant Medical Director for Gynecology, Women's Hospital, Memorial Medical Center, Long Beach, California, USA

David Charles, M.D.

Former Professor and Chairman, Department of Obstetrics and Gynecology, Marshall University School of Medicine, Huntington, West Virginia, USA

James F. Daniell, M.D.

Clinical Associate Professor, Vanderbilt University Medical Center, Nashville, Tennessee, USA

Michael P. Diamond, M.D.

Assistant Professor, Division of Reproductive Endocrinology, Department of Obstetrics and Gynecology, Yale University School of Medicine, New Haven, Connecticut, USA

JAMIL A. FAYEZ, M.D.

Professor of Obstetrics and Gynecology, Chief of Reproductive Endocrinology Section, Department of Obstetrics and Gynecology, The Bowman Gray School of Medicine, Wake Forest University, Winston-Salem, North Carolina, USA

HARRITH M. HASSON, M.D.

Associate Professor, Department of Obstetrics and Gynecology, Rush Medical College; Chairman, Department of Obstetrics and Gynecology, Grant Hospital of Chicago, Chicago, Illinois, USA 
Douglas M. Haynes, M.D.

Professor Emeritus, Department of Obstetrics and Gynecology, University of Louisville School of Medicine, Louisville, Kentucky, USA

Louis G. KeITH, M.D.

Professor of Obstetrics and Gynecology, Northwestern University Medical School, Chicago, Illinois, USA

Bryan Larsen, Ph.D.

Associate Professor of Obstetrics and Gynecology, Associate Professor of Microbiology, Marshall University School of Medicine, Huntington, West Virginia, USA

John M. Leventhal, M.D.

Clinical Instructor in Obstetrics and Gynecology, Harvard Medical School, Boston, Massachusetts, USA

Ronald L. Levine, M.D.

Clinical Professor, Department of Obstetrics and Gynecology, University of Louisville School of Medicine, Louisville, Kentucky, USA

Carl J. Levinson, M.D.

Clinical Professor, Department of Obstetrics, Gynecology and Reproductive Sciences, University of California at San Francisco; Chairman, Department of Obstetrics and Gynecology, Children's Hospital of San Francisco, San Francisco, California, USA

LINDA F. LUCAS, M.D.

Assistant Professor, Department of Anesthesiology, University of Louisville School of Medicine, Louisville, Kentucky, USA

Carolyn J. Mackety, R.N., M.A.

Director Nursing, Surgical Services, Medical Center Hospital, Burlington, Vermont, USA

JoHn L. MaRLOW, M.D.

Assistant Professor of Obstetrics and Gynecology, George Washington University School of Medicine; Assistant Clinical Professor, Department of Obstetrics and Gynecology, Georgetown University School of Medicine; Chairman, Department of Obstetrics and Gynecology, Director, Continuing Medical Education, Columbia Hospital for Women Medical Center, Washington, DC, USA

Dan C. Martin, M.D.

Reproductive Surgeon, Baptist Memorial Hospital; Clinical Assistant Professor, Department of Obstetrics and Gynecology, University of Tennessee, Memphis, Tennessee, USA 
Michael W. Method, M.D., M.P.H.

Resident, Department of Obstetrics and Gynecology, David Grant Medical Center, Travis Air Force Base, California, USA

Donald R. Ostergard, M.D.

Professor of Obstetrics and Gynecology, Director, Gynecologic Urology, University of California at Irvine, Irvine, California, USA; Associate Medical Director for Gynecology, Women's Hospital, Memorial Medical Center, Long Beach, California, USA

HARRY REICH, M.D.

Nesbitt Memorial Hospital, Kingston, Pennsylvania, USA

BENJAMin M. Rigor, M.D.

Professor and Chairman, Department of Anesthesiology, University of Louisville School of Medicine, Louisville, Kentucky USA

Joseph S. SANFILIPPO, M.D.

Professor, Department of Obstetrics and Gynecology, University of Louisville School of Medicine, Louisville, Kentucky, USA

Kurt Semm, M.D., V.M.D.Hon.

Professor and Chairman, Department of Obstetrics and Gynecology of the Christian-Albrechts-University of Kiel and Michaelis School of Midwifery of Kiel, Federal Republic of Germany

Steven R. Smith, J.D.

Dean and Professor of Law, Cleveland-Marshall College of Law, Cleveland State University, Cleveland, Ohio, USA

Marvin A. Yussman, M.D.

Professor, Department of Obstetrics and Gynecology, University of Louisville School of Medicine, Louisville, Kentucky, USA 